\title{
Teaching Chinese Language through Immortal Songs Comparing to Vietnamse Language
}

\section{Huynh Tan Hoi}

Japanese Language, FPT University, Ho Chi Minh City, VIET NAM

*Corresponding Contact:

Email: hoiht@fpt.edu.vn

Manuscript Received: 03 Feb 2019 - Revised: 22 April 2019 - Accepted: 30 April 2019

\begin{abstract}
Foreign languages in general and Chinese in particular has an important role in the context which the world has been developing continuously. Understanding and using this language eloquently will make learners have more chances to exchange culture, absorb new knowledge as well as present thoughts and views in a comfortable way. This paper mentions the reality of teaching and learning Chinese and the ways to upgrade the education quality through training practicing immortal songs as well as comparing to Vietnamese language. The article was completed with the assistance of 30 learners who are studying Chinese at some foreign language centers in Ho Chi Minh City during July of 2018 and it showed that learning process will be much more interesting and easier when listening to music.
\end{abstract}

Keywords: Chinese, teaching and learning, immortal songs, quality

This article is is licensed under a Creative Commons Attribution-NonCommercial 4.0 International License.

Attribution-NonCommercial (CC BY-NC) license lets others remix, tweak, and build upon work non-commercially, and although the new works must also acknowledge \& be non-commercial.

\section{INTRODUCTION}

For some people, it is not easy to communicate even basic Chinese sentences, not to mention the use of foreign languages as the mother tongue. They may think that Vietnamese uses the phonogram and is formed on the Latin script, while Chinese mostly use the word with many complex characters, hard to remember. Chinese pronunciation is also a challenge and not easy for beginners to learn this language. However, once learners have passion on this fascinating language, they will feel everything not that bad and have great motivation to conquer it, contributing to build themselves the richness in their soul as well as the unique aesthetic values. This will help the learner to develop the most intellectual and independent thinking (DeFrancis, 1984).

\section{CONTENT}

\section{The advantages of learning Chinese}

The interdependence between the two cultures is also a factor to help learners find it difficult to access Chinese language. Vietnam is also one of the countries that use Chinese 
characters and this kind of letter, along with its pronunciation which can supports learners a lot in the learning process. For example, when the Chinese say: 我的国家是中国 (“Wo de guojie shi zhonguo"), the word国家 ("guojie") is very similar to Vietnamese pronunciation: "quoc gia". Compared to Europeans, Vietnamese people who learn Chinese have a lot of advantages.

On the other hand, there are also many Chinese residents who are living in some areas such as Cho Lon in Ho Chi Minh City, My Tho City, Ha Tien City in Mekong Delta, or areas bordering China such as Mong Cai and Lang Son, that is, we have opportunities to talk with Chinese people. Learners can go shopping or have coffee in a small street cafe and chat with the Chinese who are easy to make conversation and rather friendly.

Moreover, Chinese and Vietnamese grammars are quite similar because the structure of these two languages is quite clear. According to Alves (2006), the common structure is the subject, then the verb and the object. When the Chinese say: "我吃米饭" ("Wo chi fan"), the Vietnamese will say: "Toi an com." ("I eat rice."). Or when the Chinese say: "我爱你" (Wo ai ni), the Vietnamese will say: "Anh yeu em." ("I love you"). This is a great advantage when communicating in a language such as Chinese that many people think is not easy to master.

\section{Benefits of using Chinese}

There are many people who are learning Chinese are wondering if what they will do in the future. However, the two most widely spoken languages in the world today are not only English but also Chinese. Chinese have become more popular than ever since China's economy is increasingly asserting its role in the world. According to the Washington Post's 2018 statistics, more than 30 million people are studying Chinese everywhere, and this language is used by a lot of native speakers in the world, surpassing English. That means if you know Chinese, you can use it almost anywhere in the world.

Chinese culture has a long history with thousands of years, including periods of ups and downs. The number of good and beautiful things not only in festivals, literature but also in other aspects that students can discover and learn much more. Many famous stories of China's vast literary treasure have been transformed into movies and have long since made many unforgettable viewers. Immortal films such as The Three Kingdoms or The Monkey King have become super-products, which if the learner understands the Chinese language itself will see more cinema works that are more attractive than ever.

Recently, Chinese goods are present in many places not only in Vietnam but around the world. Although the quality is not considered superior to that of Japan and the United States, business investment between the two countries has been going up quite positively. Speaking good Chinese, the learner will open up his own door to a variety of employment opportunities not only in Chinese companies in Vietnam but also in the job opportunities in China. Opportunities for promotion will also be very high and will get desirable salaries.

Besides, according to statistics from the Vietnam National Administration of Tourism, there are 2.6 million Chinese visitors to Vietnam in the first half of 2018, and of the 13 million international visitors to Vietnam in 2017, more than 4 million visitors are Chinese. This great potential says that if someone can use perfect Chinese and thorough tourist knowledge, they can work in the "smoke-free industry" with a comparable income. 
Not only can you do business in the tourism industry, if you know a little Chinese, you can visit beautiful landscapes such as the Great Wall or the Shin Tian Ji in Shanghai. That means you can use your own language ability when traveling without interpreting. Perhaps Vietnamese people have heard the saying: "Eat Chinese food, stay at Western houses and marry Japanese girls", and perhaps one of the three happy things of a lifetime is to enjoy the dishes in the Beijing City chosen by yourself like Beijing roast duck (北京烤鸭).

Then what to do to learn and use the Chinese well enough that many students have to think about. Learning is not just about passion, learning from books, tense learning hours, but also about language approaches through good and memorable songs.

\section{The benefits of teaching Chinese through immortal songs}

First, learning foreign languages through Chinese songs is probably one of the easiest learning methods and it does not make sense to be bored with the learners. With this learning method, learners can both learn and relieve stress when learning a new language (Salcedo, 2002).

Next is the pronunciation. The lyrics of a song can help the learner to hear and manipulate naturally. The rhythm is no longer encapsulated within a lesson but rather the rhythms are very real.

With easy songs and clear lyrics, learners can apply those words to the conversation. In addition, the grammatical structures are also a chance to help the students improve their language. Structures and vocabulary when repeated, the listeners will easily remember and application when communicating. Maybe those who are learning Chinese also know the sweet song like "The Moon Represents My Heart ": “你可我爱你值梁 (I asked you love deep he is not)

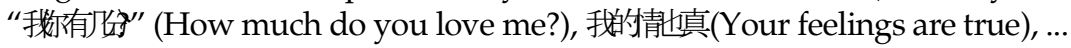

And one of the big benefits is that it improves the ability to listen to Chinese very well. To communicate well in Chinese, learners must understand and use their correct pronunciation. Therefore, when listening to regular songs, the learner will have a better vocabulary and listening comprehension skills (Salcedo, 2002).

\section{Limitations of Teaching Chinese Through Immortal Songs}

Not many students have real Chinese motivation because they do not understand the value of using this foreign language. A survey of practice methods as well as the habit of regular practice of Chinese was conducted on 30 learners of the Chinese language center in Ho Chi Minh City, as shown in the figure below.

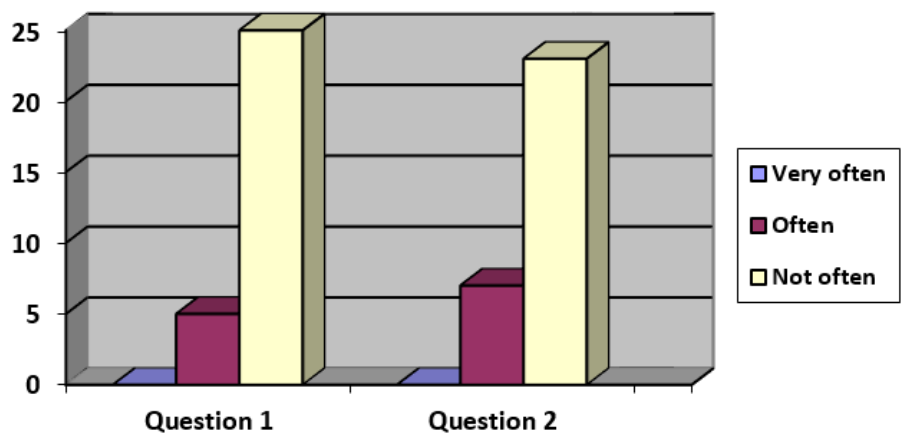

Figure: The frequency of practicing Chinese songs in class 
When asked about self-practice of Chinese language in addition to the book materials provided, very few students show interest in other methods, such as practicing the song. The first question: "Do you practice listening by listening to Chinese songs?" And the second question: "Do you watch Chinese songs on the internet or on the TV?" received the "Not often" answer.

In addition, many learners have not determined that learners have to learn by themselves, which is quite important in any field. Moreover, the use of information technology in the teaching process is not limited by the use of lecture slides as well as the use of appropriate search engines will assist in the effect (Brown, 2014; Benson, 2006).

\section{Some solutions to improve the Quality of teaching Chinese through IMMORTAL SONGS}

In order to teach Chinese, lecturers need to encourage and motivate learners to actively participate in learning. They need to have an interesting focus when the instructor asks them to rehearse new words, practice vocals together. Teachers also need to listen to students regularly every week to give them positive listening habits. Trainers also need to grasp the psychology of the learner, creating comfort for learners. Not all learners are confident or energetic, so teacher should ask students to participate in learning activities to gain confidence in communication.

The application of information technology in teaching to suit the content of the lesson to create attraction. Slides lectures in the form of lyrics design, lecturer can use gap-filling method to complete the in the task. Songs and slides need to be repeated two to three times until the learner completes. The words that need to be filled in should also be selected to match the level of the class, ensuring that it is not too easy nor too difficult (Salcedo, 2002).

For students, lecturer should direct them to relevant materials, good and accessible songs. Students can find materials for references from books, newspapers, the internet, or Chinese television program to improve his foreign language skills.

\section{CONCLUSION}

Teaching and learning Chinese or any other foreign languages, teachers should always find and apply the most effective teaching methods such as how to use songs in Chinese. In addition, the passion, interest in Chinese as well as the initiative in learning on their own will help them will be easier to succeed. In this way, the trainers can transfer knowledge to the students to motivate them to easily conquer the foreign language and have better future opportunities.

\section{REFERENCES}

Alves, Mark. (2006). Linguistic Research on the Origins of the Vietnamese Language: An Overview. Journal of Vietnamese Studies. 1. 104-130. 10.1525/vs.2006.1.1-2.104.

Benson, P. (2006). Autonomy in Language Learning. Retrieved from http:/ /ec.hku.hk/autonomy/what.html> and <http:/ / ec.hku.hk/autonomy/\#k.

Brown, H. Douglas. (2014). Principles of Language Learning and Teaching. Pearson Education ESL; 6 edition.

DeFrancis, John. (1984). The Chinese Language: Fact and Fantasy. Honolulu: University of Hawaii Press.

Salcedo, Claudia Smith. (2002). The effects of songs in the foreign language classroom on text recall and involuntary mental rehearsal. LSU Doctoral Dissertations. 1458. Retrieved from http://digitalcommons.lsu.edu/gradschool_dissertations/1458.

$$
--0--
$$

